\title{
CARTOGRAFIA DIGITAL E GEOMORFOLOGIA URBANA APONTAMENTOS PARA O ENSINO DE GEOGRAFIA
}

\author{
Abraão Levi dos Santos Mascarenhas ${ }^{(a)}$ Maria Rita Vidal ${ }^{(b)}$ \\ (a) Faculdade de Geografia, Universidade Federal do Sul e Sudeste do Pará, abraaolevi@ hotmail.com \\ (b) Faculdade de Geografia, Universidade Federal do Sul e Sudeste do Pará, mritavidal@yahoo.com.br
}

\section{EIXO: GEOGRAFIA FÍSICA: CURRÍCULO, FORMAÇÃO E PRÁTICAS DE ENSINO}

\begin{abstract}
Resumo
O ensino de geografia vêm passando por transformações significativas no que concerne o desenvolvimento das ferramentas computacionais, alguns conteúdos no ensino de geografia vêm sendo legado a segundo plano, a saber o ensino do relevo, este é retrato como tema de geomorfologia e/ou topografia se convertendo, muito das vezes, como confusão teórica e metodológica. O principal objetivo dessa secção é reafirmar que a construção e o uso da maquete se mostra como um instrumento didático no ensino básico, pois envolve a representação espacial de temas da cartografia e topográfia, permitindo, ainda, desenvolver os temas de geomorfologia urbana. O uso dos temas geomorfologia urbana, representação espacial e cartografia digital geomorfológica é a principal questão metodológica que balisa a presente discussão. Conclui-se que a maquete é um instrumento didático para a formação dos conceitos de relevo no ensino básico.
\end{abstract}

Palavras chave: Geomorfologia; representação e ensino.

\section{Introdução}

A necessidade da busca de um ensino de geografia pautado sobre o signo da crítica têm sido o desafio de nós professores - em um mundo que muito oferece informação e pouca formação há um hiato entre a formação universitária e a transposição didático-pedagógica. Contudo as pesquisas, de uma forma geral, vêm demonstrando caminhos e alternativas para se implementar um ensino de geografia comprometido com as realidades cotidianas.

Seguindo nessa direção observarmos que o ensino de geografia física, via livro didático, vem sendo diluído em temas ditos transversais como a questão do meio ambiente ou abordados em estudos da natureza balizados pelo conceito de paisagem, daí as questões do relevo é claramente insuficiente. Se levarmos em consideração o tema de cartografia podemos observar que em alguns momentos ele é quase inexistente, alguns livros didáticos organizam os conteúdos em secção do anexo da obra.

Esse panorama geral nos chama atenção e nos coloca um desafio, como desenvolver uma metodologia viável, de fácil manuseio, exeqüível para os professores do ensino básico realizarem intervenções metodológicas junto ao conteúdo específico como o estudo do relevo? Como abordar de forma clara, respeitando a realidade local dos discentes, o estudo das formas do relevo? A maquete! Pensariam alguns, 
assim como se daria a construção dessa maquete quando não se tem disponíveis cartas bases? Como se utilizar de bancos de dados capazes de auxiliarem na construção das cartas topográficas para a retirada das curvas de níveis?

O uso da linguagem cartográfica digital, a geomorfologia urbana e o conhecimento das ferramentas de Sistemas de Informações Geográficas (SIGs) são aliados capazes de diminuir o fosso entre a formação acadêmica do licenciado e a sua atuação como professor no ensino básico, já que as ferramentas geotecnológicas vem se tornado, para o ensino, uma tecnologia de informação e comunicação.

Assim é que acredita-se que a construção de modelos dinâmicos e de representação das formas de relevo a partir das imagens de Radar (com dados de variação de altitude da superfície terrestre), em especial a da missão SRTM, para subsidiar as aulas de geografia no ensino médio, visando análise a dinâmica dos sistemas naturais e os sistemas humanos em perímetro urbano.

O ensino de geografia sempre esteve ligado aos avanços científicos, tecnológicos e as necessidades de organizar a dinâmica da sociedade sobre o espaço, fruto da ação humana da dinâmica dos sistemas naturais. Nesse sentido temos o espaço urbano dominado pelos objetos técnicos (SANTOS, 1996), e pela dinâmica dos ambientes naturais. (ROSS, 1994). A dinâmica do espaço urbano é fruto da imbricação dos objetos técnicos e dos ambientes natural pouco visto por aqueles que planejam a cidade, enchentes, colapsos e movimentação de massa são eventos que costumam afetar os citadinos, nesse panorama a disciplina de geografia pode auxiliar no entendimento de toda essa dinâmica, em especial, o estudo de geografia física pelo viés da Geomorfologia.

A geomorfologia como base física de toda ocupação humana, tem potencial pedagógico que possibilita a compreensão dos principais eventos naturais que a cidade possui, por isso, urge instrumentalizar professores, graduando e alunos com o uso dos estudos de geomorfologia no ensino de geografia. Para esse processo de intervenção pedagógica a utilização de imagens de Radar e a construção de maquetes sobre o relevo se expressa por ser um instrumento metodológico útil nas aulas de Geografia.

A cartografia digital e a geomorfologia urbana inserida no ensino de geografia pode apresentar algumas situações de dificuldades instrumental e pedagógicas. O Instrumental refere-se ao dilema de incluir a linguagem das tecnologias de informações e comunicação (TIC's), nesse sentido o uso da informática, utilização dos Sistemas de Informações geográficas (SIGs) e seus respectivos bancos de dados. Nas questões pedagógicas enfrentasse a questão da transposição didática (CHEVALLARD, 1991) em relação os conceitos da geomorfologia e o ensino de geografia física em ambiente escolar. 


\section{OS DESAFIOS DA GEOGRAFIA FÍSICA NA FRONTEIRA DO CONHECIMENTO \\ Instituto de Geociências - Unicamp \\ Campinas - SP \\ 28 de Junho à 02 de Julho de 2017}

Dessa forma, o objetivo do trabalho versa sobre a busca da afirmação de que a construção e o uso da maquete se mostra como um instrumento didático adequado ao ensino básico. Os caminhos iniciais apontam a necessidade de uso de novas linguagens e novas posturas diante das realidades impostas sobre o município e consequentemente sobre a forma de ensinar e aprender geografia em busca de uma cidadania, pois assim é possível analisar as formas de pensar e agir das pessoas sobre o relevo e a formação de paisagens urbanas a partir da representação espacial e seus filtros de percepção e cognição.

\section{Metodologia}

\subsection{A representação espacial como linguagem interdisciplinar no ensino de Geografia}

A representação como construto social se realiza a partir de esquemas pertinentes do real, é peça chave, essencial a explicação das relações dos homens com seu modo de vida, assim é que Bailly (1990) afirmar que o real objetivo não existe fora do construído. A representação enquanto ponto de vista e qualidade da percepção humana constitui-se um fenômeno mental bem como pode ser visto no trecho a seguir:

Uma representação é um fenômeno mental que corresponde a uma reunião mais ou menos consciente, organizada e coerente, de elementos cognitivos, afetivos e de domínio de valores concernente a um objeto particular. Onde encontra-se elementos conceituais de atitudes, valores, imagens mentais, conotações, associações, etc. Esse universo simbólico, culturalmente determinado onde forja-se a teoria espontânea, as opiniões e os "pré-conceitos" as decisões de ações, etc. (GARNIER ET SAUVE, 1999, p. 66 Apud PARTOUNE, 2004).

Pensando na perspectiva da paisagem enquanto representação mental, Cristine Partoune (2004) afirma que a incorporação de símbolos e conceitos culturais no decorrer dos tempos se consolida como um ponto de vista intelectual, mobilizados por processos de abstração. Os fatores que contribuem para essa consolidação dizem respeito ao nível de instrução, o meio sócio-cultural, a educação e a categoria profissional.

O sistema de filtro é o recurso didático para construção de uma realidade elaborada pelos indivíduos, a paisagem aqui é o conceito que dá sentido a nossa afirmação, já que na paisagem a percepção, a cognição e o aspecto físicos são essenciais para montar um quadro geral da formação de uma paisagem.

A construção da paisagem objetiva retratadas pelo sistema de filtro nos remete as formas de representação que encontramos no ensino de geografia como as maquetes, mapas e croquis dos quais são construídos a partir da percepção, nível de cognição de quem o constrói. A figura 1 é a síntese de nossa afirmação. 
XVII Simpósio Brasileiro de Geografia Física Aplicada

I Congresso Nacional de Geografia Física
OS DESAFIOS DA GEOGRAFIA FÍSICA NA FRONTEIRA DO CONHECIMENTO

Instituto de Geociências - Unicamp

Campinas - SP

28 de Junho à 02 de Julho de 2017

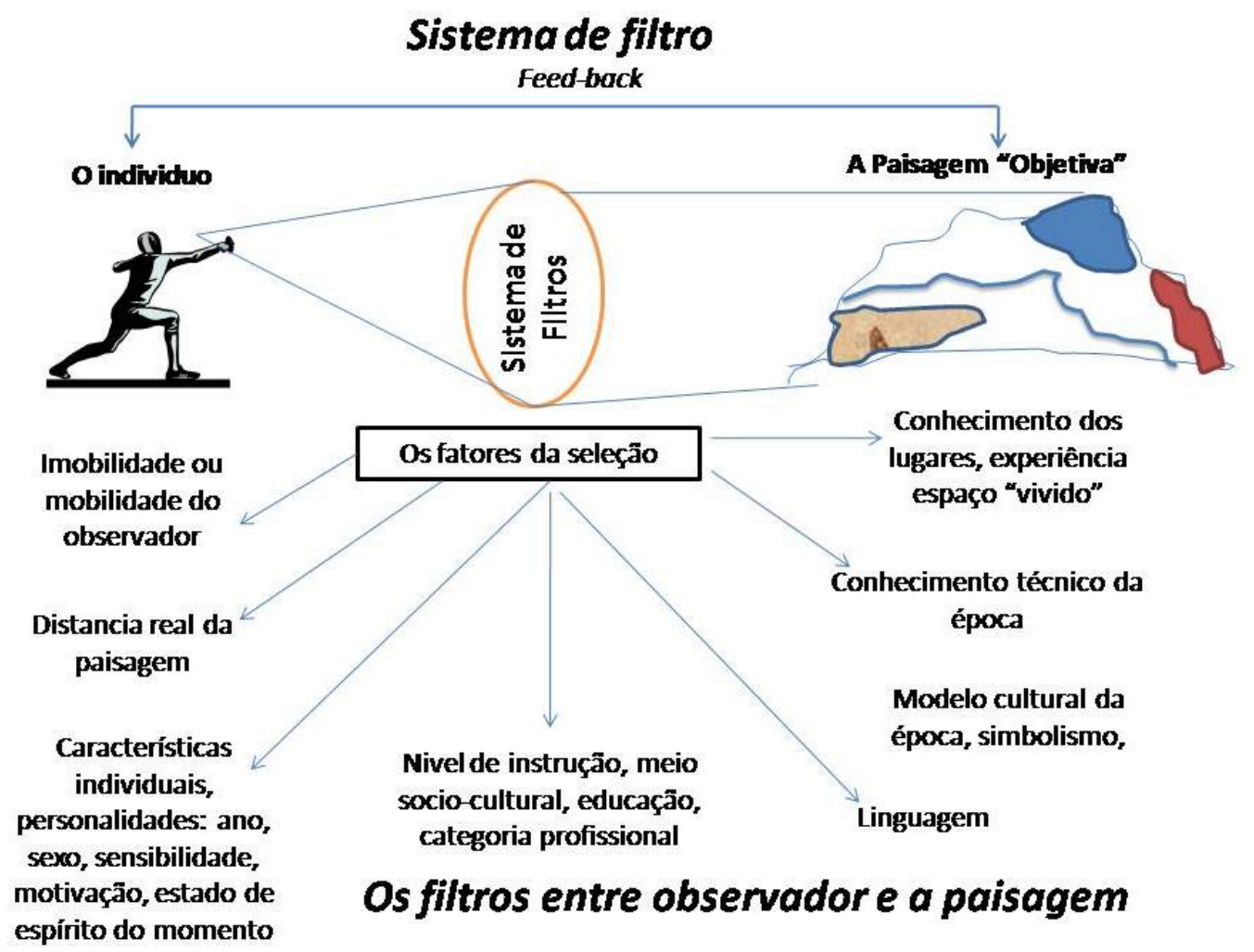

Figura 1- Sistema de filtros entre observador e a paisagem.

Fonte: Paulet (2002) Apud Partoune, 2004.

Assim a possibilidade de trabalhar com representação espacial recai na necessidade de atentar para os fatores de seleção tanto do docente quanto do discente a partir dos filtros fisiológicos e sociais. A partir da perspectiva fisiológica onde o sistema nervoso central é ativado através do olho, dando possibilidade de uma primeira interpretação dos elementos constitutivo da paisagem. Quando fala-se de filtro social relacionamos aos fatores ligados ao ensinamento dado pela cultura (BAILLY; RAFFESTIN e REYMOND, 1980). É mister compreender, que o encontro de vários filtros na escola é inerente a prática do ensinar, essa prática contextualizada com a realidade local potencializar o ensino de geografia transformando a sala de aula em locus da construção de novos conhecimentos. A forma de ver a realidade por outros filtro é a missão do ensino de geografia.

Quais seriam então os novos filtros necessários à prática docente? Pode-se apontar pelo menos três: a) a geomorfologia urbana; b) a representação espacial e c) cartografia digital geomorfológica. 
XVII Simpósio Brasileiro

de Geografia Fisica Aplicada

I Congresso Nacional

de Geografia Física
OS DESAFIOS DA GEOGRAFIA FÍSICA NA FRONTEIRA DO CONHECIMENTO

Instituto de Geociências - Unicamp

Campinas - SP

28 de Junho à 02 de Julho de 2017

a) Geomorfologia Urbana - como ciência responsável pelo estudo da gênese e das formas de relevo a partir das cidades tem uma abrangência sobre a análise da paisagem construída ou paisagem derivativa das ações da sociedade sobre o meio físico. Então a construção de filtros sobre os conceitos básicos das formas e das dinâmicas do relevo a partir das intervenções humanas auxiliam no entendimento de fenômenos físicos que acontecem na cidade.

b) É possível relacionar a representação espacial com as questões espaciais topológicas, projetivas e euclidianas no momento em que a representação espacial é um contínuo das operações concretas, seguidas de operações interiorizadas.

c) Cartografia Digital Geomorfológica - existem vários sistemas de mapeamento geomorfológico que servem para classificar o relevo, não há um padrão único de sistemas cartográfico para a representação do relevo, mas podemos destacar no Brasil os modelos de Tricart (1965); Ab’Saber (1969) e de Ross (1990), pontuados por Florezano (2008).

A Associação de estruturas e formas de relevo são os fatores geomorfológicos para definir mapas de relevos, a questão do tempo é retratada pelas regiões geomorfológicas inseridas nos conjuntos litoestruturais definindo a gênese da característica comum sobre a ação passada e presente do clima. O objetivo mais importante da cartografia geomorfológica é a espacialização dos fatos geomorfológicos, que de acordo com Casseti (2005) permite representar a origem das formas, relações, processos e dinâmica do relevo. Nesse contexto os mapas geomorfológicos servem como subsídios para o início dos inventários físicos-naturais e balizadores para definir formas de uso e ocupação racional do relevo. (ROSS, 1990).

Para o ensino de geografia o entendimento das formas de relevo deve ser realizado com ajuda de recursos visuais e de estudo do meio, já que ambas metodologias se intercruzam para fornecer competências e habilidade aos discente, além do mais, possibilita a compreensão do fenômenos físicos no ambiente urbano como enchentes, alagamentos, deslizamento de terras, etc.

Assim, é possível a instrumentalização de forma efetiva o ensino de Geografia nos temas de meio ambiente e recursos naturais. Aulas expositivas e dialogadas sobre geomorfologia, paisagem e espaço urbano, e o texto de Mascarenhas; Vidal (2014) sobre a declividade e hipsometria do perímetro urbano da cidade de Marabá-PA são exemplos de estudos específicos que dão subsídios importantes para dialogar e debater e criar um clima de cordialidade parceria e troca de conhecimento sobre os aspectos físicos da cidade.

A produção de carta topográfica gerada a partir de curvas de níveis em meio digital é a base para a produção da maquete - a impressão no plotter deve ser em papel A0, do qual conservar a 


\section{OS DESAFIOS DA GEOGRAFIA FÍSICA NA FRONTEIRA DO CONHECIMENTO \\ Instituto de Geociências - Unicamp \\ Campinas - SP \\ 28 de Junho à 02 de Julho de 2017}

proporcionalidade do perímetro urbano da cidade. As curvas de níveis podem ser geradas em curvas mestre de 30 metros, gerando isolinhas de 100, 120 e 140, ideais para transpor para as folhas de isopor com 10 milímetros de espessura. Na figura 2 temos um exemplo de ambiente SIG preparado para a geração de carta topográfica.

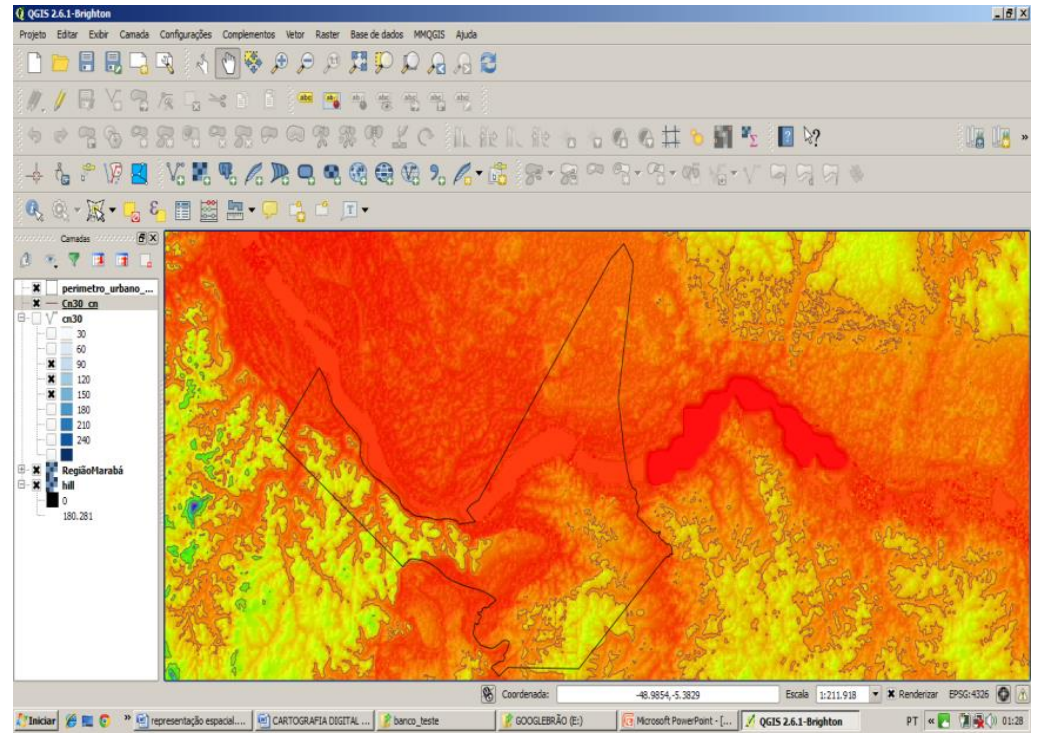

Figura 2 - Ambiente SIG para confecção de Carta topográfica.

Organização: Autores (2015).

O uso e manipulação do software QGis e a construção do banco de dados é realizado com a ajuda da internet, seja para realização do dowloand, "baixar", o pacote do software de SIG para posterior uso off line, seja no uso bancos de dados associados ao IBGE, CPRM, ANA e outros bancos de dados disponibilizados na internet.

Para completar a construção da carta topográfica há necessidade da realização do mapa geomorfológico, a partir de um ambiente sedimentar, por exemplo, uma bacia hidrográfica, unidade de planejamento é uma paisagem interessante para ser utilizada para rios urbanos, o quadro abaixo é uma preposição de legenda para a construção do mapa de geomorfologia urbana para a cidade de Marabá-PA, ver Figura 3.

\begin{tabular}{|l|l|l|l|l|}
\hline $\begin{array}{l}\text { Elementos Morfoesculturais } \\
\text { ou Macrocompartimentação }\end{array}$ & $\begin{array}{l}\text { Categorias } \\
\text { Morfológicas }\end{array}$ & Topografia & Litologia & $\begin{array}{l}\text { Associação } \\
\text { de Solos }\end{array}$ \\
\hline $\begin{array}{l}1.0 \text { Depressão do Tocantins } \\
\text { Araguaia }\end{array}$ & $\begin{array}{l}1.1 \text { Colinas } \\
\text { pequenas e médias }\end{array}$ & $31-80 \mathrm{~m}$ & $\begin{array}{l}\text { Arenito } \\
\text { fino, }\end{array}$ & Latossolo \\
\hline
\end{tabular}


Instituto de Geociências - Unicamp

Campinas - SP

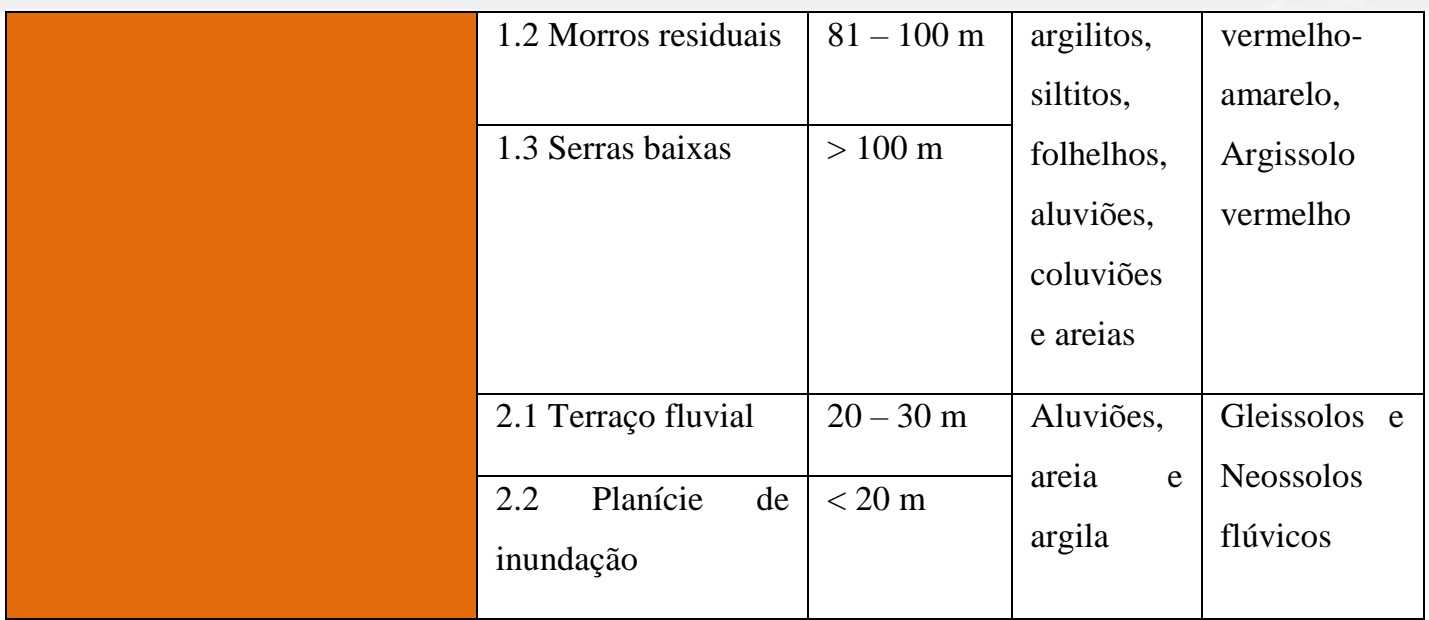

Figura 3 - Proposta de legenda para a construção do mapa de geomorfologia urbana.

Organização: Autores (2015).

O Ambiente Sig permite individualizar a carta topográfica, facilitando a impressão das curvas de nível necessária à produção da maquete, ou seja, o SIG sendo um ambiente bidimensional possibilita a transformação de maquetes em ambiente tridimensional. Tem a possibilidade de sair do abstrato, Figura 4 (carta topográfica) para o concreto (Maquete de Isopor ou E.V.A), Vidal e Mascarenhas (2013).

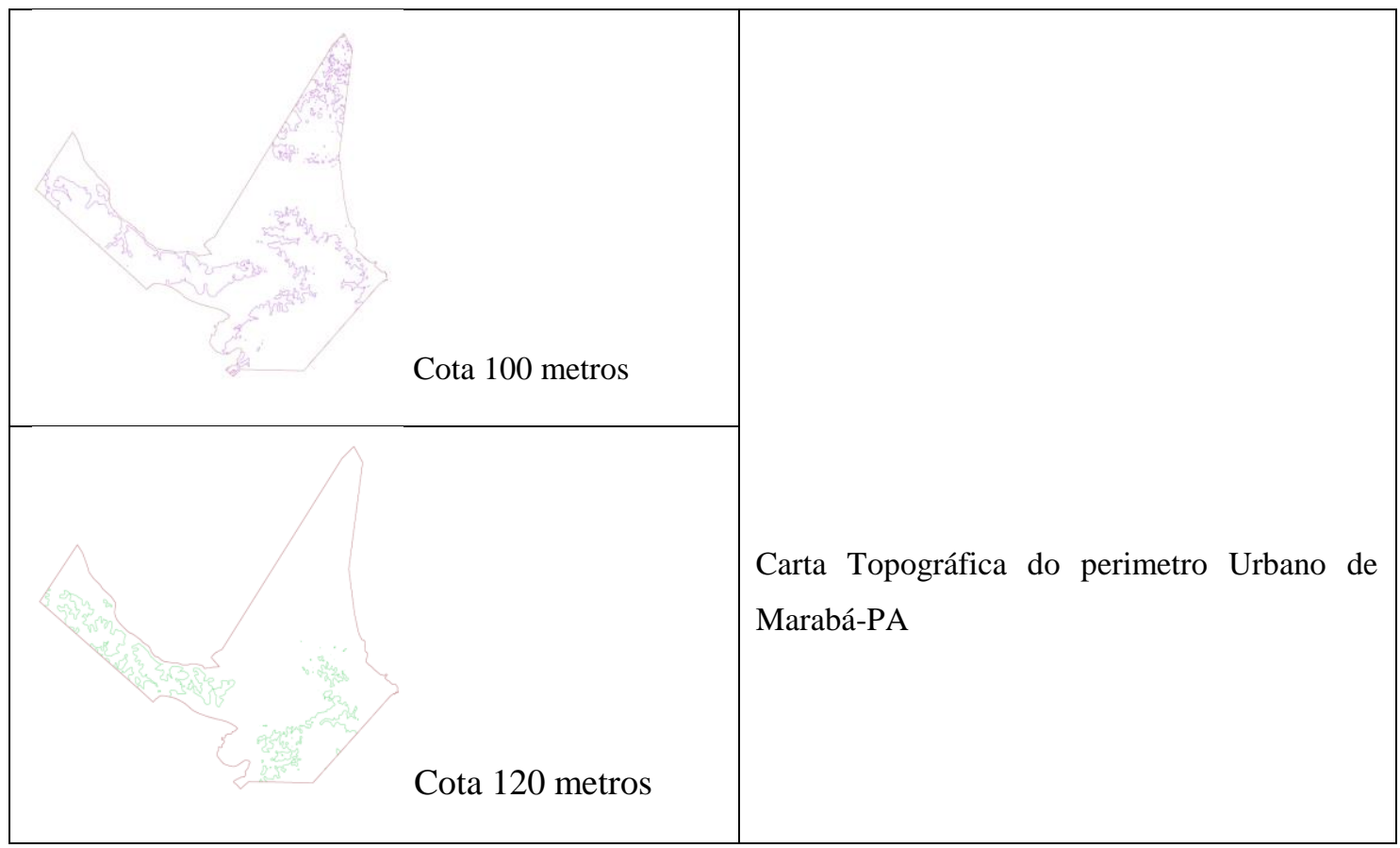




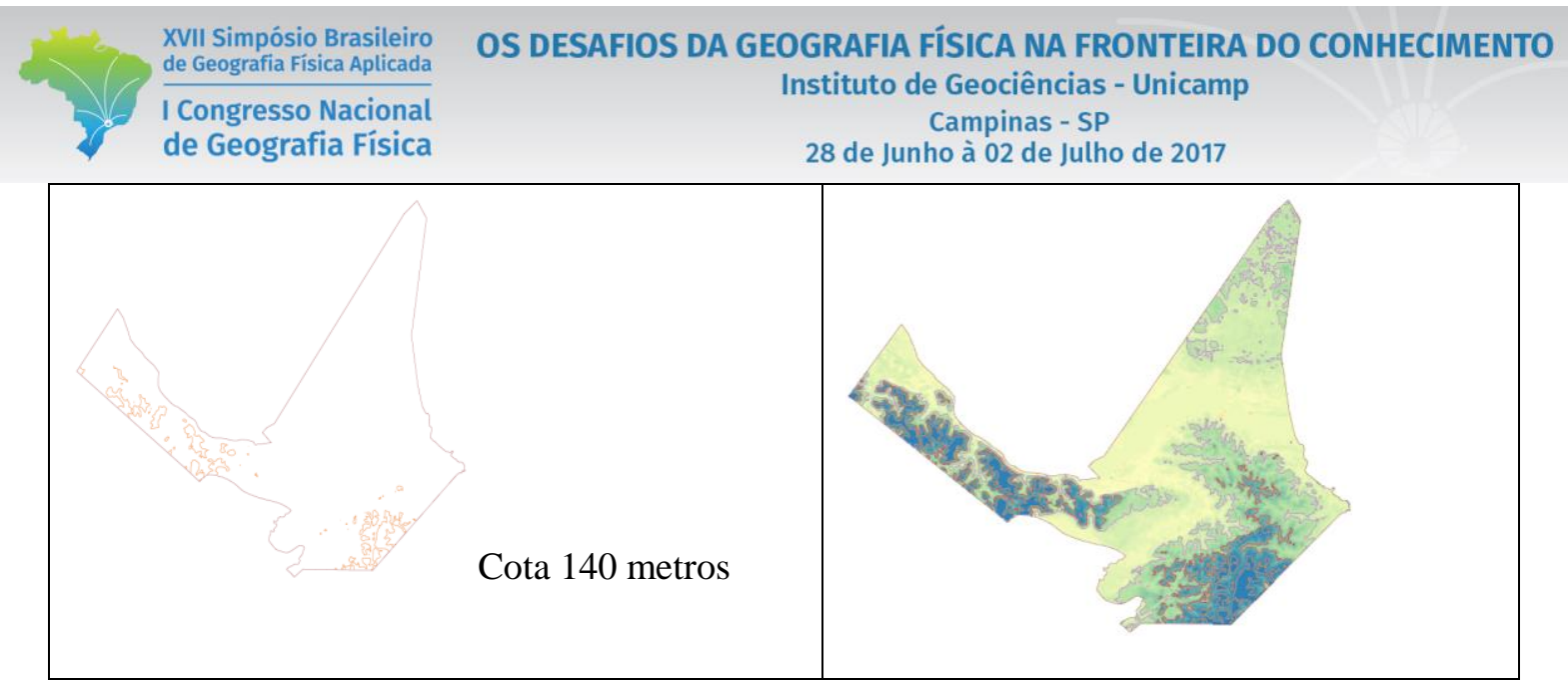

Figura 4 - Carta topográfica com curvas de níveis individualizadas.

Organização: Autores (2015).

Assim pode-se perceber que a construção da carta topográfica e a questão da produção do espaço urbano são elementos essenciais na discussão da dinâmica ambiental nos espaços urbanos, a geomorfologia urbana é eixo central no ensino da geografia física, em especial, no ensino da geomorfologia em caráter regional e local.

\section{Resultados e discussões}

\subsection{A maquete como instrumento didático para a formação dos conceitos de relevo no ensino básico}

Uma das maiores dificuldade no ensino básico é o tema de relevo, pois ele aparece como conceitos da ciência geomorfológica atrelado aos conceitos de topografia, essa confusão conceitual pode ser advindo da necessidade de didatizar os temas de geografia física no ensino básico - E assim a questão da transposição didática não acontece de forma satisfatória proporcionando uma confusão teórica em relação as questões geomorfológicas que podemos encontrar nas áreas urbanas.

A maquete é um instrumento didático possível de organizar as informações dos temas relevo, geomorfologia e topografia (altimetria, curvas de níveis, etc.), desfazendo a confusão conceitual visto com muita frequência nos livros didáticos. De outra maneira a construção da maquete permite apreender os conceitos de topografia, em especial as questões das curvas de níveis, cotas topográficas em um ambiente de duas dimensões (2D), ou como alguns autores colocam como a dimensão abstrata da carta topográfica. Ao destacar as curvas mestras da carta topográfica e sua transposição para materiais como Isopor ou E.V.A possibilita a visão de terceira dimensão (3D), ou como de costuma chamar de visão concreta.

Posto as cotas em ambiente 3D a maquete torna-se um instrumento didático para trabalhar as questões geomorfológicas, assim é possível trabalhar temas como planícies fluviais, tabuleiros costeiros, tabuleiros 


\section{OS DESAFIOS DA GEOGRAFIA FÍSICA NA FRONTEIRA DO CONHECIMENTO \\ Instituto de Geociências - Unicamp \\ Campinas - SP \\ 28 de Junho à 02 de Julho de 2017}

interiores, planaltos dissecados, redes de drenagem, ou seja, ao passo que cada instrumento técnico vai sendo desenvolvido, outras informações irão sendo trabalhadas no decorrer das aulas.

Assim é que para além de um recurso metodológico a maquete torna-se instrumento de aprendizagem desfazendo confusões de ordem teóricas e conceituais posto que entendem-se cada elemento da carta topográfica, elementos dos mapas de geomorfologia. Então é que a maquete contém elementos técnicos de representação espacial que possibilita construir um conhecimento geográfico.

\section{Considerações Finais}

Pensando no desenvolvimento dos conteúdos de geografia física (geomorfologia urbana), os sistemas de informação geográfica possibilitam diminuir as dificuldades da produção de materiais didáticos para o ensino de geografia. Sabe-se que a popularização dos SIG's não necessariamente chega aos profissionais do ensino básico. Por isso o caminho é a formação continuada dos professores do ensino básico, essa formação exige conteúdos de cartografia básica e temática, noção de sensoriamento e geoprocessamento e conhecimento de sistemas de informações geográficas. Esses conteúdos serão incluídos nas questões da linguagem e representação no entendimento dos fenômenos geográficos.

A forma de comunicar os elementos cartográficos, topográficos e geomorfológicos ganham novos espaços no ensino básico por permitir que a maquete seja esse instrumento didático capaz de envolver representações espaciais (cartas e mapas) e ensino de Geografia pelos filtros sociais, aquilo que é inerente ao filtro social relacionado aos fatores ligados ao ensinamento dado pela cultura em geral.

Reafirma-se que a maquete é um instrumento didático útil na formação do conhecimento geográfico fortalecendo as bases de uma educação geográfica pronta a atuar como elemento da formação crítica cidadã. A transposição didática é o elo essencial entre o conhecimento universitário/acadêmico e a educação básica, essa "sinergia pedagógica" torna a Ciência Geográfica fascinante por apresentar o mundo através da maquete e seus elementos de geografia física.

Por fim cabe saber que as ferramentas de geoprocessamento só poderão ser útil se usada como auxiliar junto as práticas de ensino em nem um momento os software e as máquinas poderão substituir os professores (as) na tarefa de formação e condução de cidadã comprometido com a construção de um espaço geográfico mais equitativo e possível de se viver. 


\section{REFERÊNCIAS}

BAILLY. Antoine Sylvain. Paysages et représentations. In: Mappemonde, 1990, no. 3, p. 10-13

. RAFFESTIN, Claude, REYMOND, Henri. Les concepts du paysage: problématique et représentations.

Espace géographique, 1980, vol. 9, no. 4, p. 277-286.

CASSETI, Valter. Geomorfologia. [S.1.]: [2005]. Disponível em: 〈http://www.funape.org.br/geomorfologia/>.

CHEVALLARD, Yves. Latranspositiondidactique: dusavoirsavantausavoirenseigné. Grenoble: Ed. La PenséeSauvage, 1991.

FLORENZANO. Teresa G. (Org.) Geomorfologia: conceito e tecnologia atuais, São Paulo, Oficina de Texto, 2008.

MASCARENHAS, A. L. S.; VIDAL, M. R. Declividade e Hipsometria do perímetro urbano da cidade de MarabáPA: aportes conceituais de geomorfologia urbana. In: Anais...VII Congresso Brasileiro de Geógrafos, 2014, VitóriaES. AGB-Nacional, 2014. v. 1.

PAULET J.-P., 2002. Les représentations mentales en géographie, Paris, Anthropos, coll. Géographie.

PARTOUNE. Christine. La dynamique du concept de paysage. In: Revue Éducation Formation - $\mathrm{n}^{\circ} 275$, septembre 2004.

ROSS. JurandyrLuciano Sanches. Análise empírica da fragilidade dos ambientes naturais e antropizados. In: revista do departamento de geografia, USP, São Paulo,v. 8, 1994.

SANTOS, Milton. A natureza do Espaço: Técnica e Tempo, Razão e Emoção, 4. ed. 2. Reimpr, São Paulo: Editora da Universidade de São Paulo, 2006. 1988.

Metamorfoses do espaço habitado: fundamentos Teórico e metodológico da Geografia. Hucitec, São Paulo

VIDAL, M. R., MASCARENHAS, A. L. S. Da abstração ao concreto: representação espacial no ensino de cartografia In: Ensino de Geografia e representação do espaço geográfico.1 ed.Belém-PA : GAPTA-UFPA, 2013, v.1, p. 291-306. 